\title{
Application of Scaffolding in Combination with Other Teaching Strategies in Translation Lessons among Senior High School Students in China
}

\author{
Longxiang Shen*, Yu Zhao, Shangyang Wang \\ Leshan Normal University, Leshan 614000, Sichuan Province, China
}

\begin{abstract}
This study measures the effectiveness of combining group discussions, pre-questionings, or both with scaffolding teaching strategies in translation lessons based on Angelelli's translation competence model. However, in practice, the feasibility of using the Angelelli's scoring scale to measure translation competence requires further verification by other empirical studies. The results of this study are only for reference, in hope that future researchers may contribute to the improvement in this subject.
\end{abstract}

Keywords: Scaffolding; Translation; Teaching

Publication date: May, 2021; Publication online: 31 May, 2021

*Corresponding author: Longxiang Shen, 1439512379@qq.com

Scaffolding is first described as an educational strategy (Wood, Bruner \& Ross, 1976). However, this concept dated back to the beginning of human history when parents used this strategy to teach their children to walk and talk. Applying to the education system, the concept of scaffolding as a teaching strategy was derived from Vygotsky's concept of assisted learning and associated with his sociocultural theory of development. According to Vygotsky, scaffolding takes place within students' zone of proximal development (ZPD), and he defined this zone as "the distance between the actual developmental level as determined by independent problem solving and the potential development under adult guidance or in collaboration with more capable peers." Simply put by Harris and Pressley, the zone of proximal development is the "area between what a learner can do independently (mastery level) and what can be accomplished with the assistance of a competent adult or peer (instructional level)."

In previous studies, some scholars believed that the scaffolding strategy in teaching is used in the interactive relationship between "teaching" and "learning" to stimulate students' interests in learning. This may compensate for the shortcomings of traditional translation teachings, whereby teachers dominate the classroom. The traditional translation teaching method is based on the "Stimulus-Response" theory. Hence, translation lessons are "teacher-centered" with only one type of learning environment which comprise of teachers, students and textbooks." ${ }^{[3]}$ According to Spolsky, by introducing different teaching activities in translation lessons, students will be able to cultivate good habits of reflection, thus improving translation skills. Pre-questionings may help students realize the importance of these questions, hence, encouraging students to form a thinking pattern in order to apply them when translating. American linguist and translation theorist, Eugene A. Nida believes that without a thorough understanding of the original text, translation can only be a mechanical conversion of words. In González-Davies experience as a professional translator trainer, progressive approaches to learning (eg. González-Davies 2004; Kelly 2005; Nord 2005) and appropriate 
scaffolding are essential. However, cognitive constructivist and situatedness-based philosophers are fastidious about the supporting tasks that they find acceptable. The scaffolding strategy may not appeal to dogmatic socio-constructivism (SC) theorists because it implies 'dissecting' knowledge or skills to complete a given task or action and focusing on specific problems of a complex task in a piecemeal fashion. At present, there are a few research on the development of teaching models related to English translation teaching among senior high school students in China.

As mentioned above, traditional teaching is based on the "Stimulus-Response" theory whereby, the teachers' main role is to impart knowledge from textbooks to the students, while the students need to digest and understand the information given. In the traditional teaching of translation, theoretical lectures regarding translation skills are given which will be consolidated by exercises. This is often referred as the stereotypical "Teach-PracticeCorrect." The "teacher-centered" method which regards correcting mistakes using the teacher's translation as reference, does not conform to the characteristics of translation. To a certain extent, it stifles the enthusiasm and creativity of students in the translation practice, hence, students may find it boring and challenging to learn this skill. This method suppresses their confidence in the practice of translation. Our research studied the application of the scaffolding strategy among senior high school students to enhance their confidence and interest in English translation practices.

A study was carried out in order to determine the effects of different teaching activities on students' translation skills using the scaffolding teaching strategy. A total of 80 Grade One students in Leshan No. 1 High School were enrolled as subjects. Their translation skills were generally the same. Translation materials were selected from the Grade Two English textbook, whereby the subjects were not familiar with them. The materials comprised of words, phrases, grammar in the form of texts (Text 1, Text 2, Text 3).

In order to control variables and achieve accurate results, all the subjects were required to translate the text, "At that time I discovered blogging and found that...part of the solution" (Text 1), prior to the translation lesson. The text was taken from the FLTRP High School English Compulsory 2, Unit 5 textbook. Then, gradings were given to each student according to Angelelli's translation scoring scale. According to Angelelli, the scoring scale focused on the ability to comprehend the original text and expression of the theme in the translated text. There were five grading levels, whereby Level 5 represented the highest quality translation, while Level 1 represented the poorest. Further descriptions of these levels are as following: Level 5 indicates that the translation reflects detailed understanding of the major and minor themes of the original text, differentiated subtle points, reproduced the expression of the original text, and skillfully communicated its' meaning. Level 4 indicates that the translation reflected full understanding of the major and minor themes, reproduced the expression of the original text, and skillfully communicated its' meaning. Level 3 indicates that the translation reflects basic understanding of the major and minor themes, reproduced the expression of the original text and communicated the overall meaning with occasional errors. Level 2 indicates that there were deviances in understanding the major or minor theme or expressions of the original text, and there were interpretation errors, thereby the overall meaning is not communicated. Level 1 indicates that the translation showed major misunderstanding in the original meaning of the text (Angelelli 2006:41). The students were then divided into four different groups (Group A, B, C, and D), whereby each group consists of 20 students.

This study was conducted to measure the effectiveness of combining group discussions, prequestionings or both with scaffolding teaching strategies (hints or references were given). Students were divided into two experimental groups and two control groups (Group A, B, C, and D, respectively), whereby all of them were taught using the scaffolding strategy. Students in Group A were allowed to have group discussions during translation lessons while students in Group B were 
given some guided questions prior the translating lesson. On the other hand, students in Group $\mathrm{C}$ were taught by scaffolding teaching strategy only while Group D were taught using the scaffolding teaching strategy in combination with both, group discussions and pre-questionings.

The teacher then carried out the teaching lessons for a week corresponding to the methods mentioned above. Each lesson lasts for 40 minutes a day. The teaching material was "Twenty Thousand Leagues under the Sea" (Text 2) from the FLTRP High School English Compulsory 3, Unit 5 textbook.

After a week, the four groups sat for the translation test using Text 3, and scores were given to each student according to Angelelli's translation scoring scale. Comparing the test scores from translating Text 1 (prior lessons) and Text 3 (after lessons) of the four groups, the variates of each group were calculated.

The study found that compared to group A, students in group B (completed translation task through pre-questionings) have significant improvements in translation skills, thus reaching level 4 in the Angelelli's scale (the translation reflects the understanding of the major and minor themes, reproduced the expression of the original text and skillfully communicated its' meaning). Although students in group A completed the task through group cooperation, their grading level remained at level 3 (the translation reflects the basic understanding of the major and minor themes, reproduced the expression of the original text and skillfully reproduced its' meaning with occasional mistakes) possibly due to the lack of appropriate guidance through pre-questionings. Despite Group B's results, the research found that Group D (given pre-questions, and had group activities) have reached the level 5 scale (the translation reflects detailed understanding of the major and minor themes, differentiated subtle points, reproduced the expression of the original text, and skillfully communicated its' meaning). The results of Group $\mathrm{C}$ were not satisfactory as their level dropped. This is because this group only had reference materials from the teacher, without any group activities or teacher's guidance via questions. Therefore, a conclusion is drawn. Using the scaffolding strategy with the combination of pre-questionings and group discussions have the most significant effect on the improvement of students' translation skills.

This study measures the effectiveness of combining group discussions, pre-questionings or both with scaffolding teaching strategies in translation lessons based on Angelelli's translation competence model. However, in practice, the feasibility of using the Angelelli's scoring scale to measure translation competence requires further verification by other studies. The results of this study are only for reference, in hope that future researchers may contribute to the improvement of this matter.

\section{Disclosure statement}

No conflicts of interest.

\section{References}

[1]Wei, J. The Application of Multi-modal Auxiliary Scaffolding Teaching Method in College English Translation Teaching.

[2] Wang. L. The Application of Scaffolding Teaching Model in English Translation Course.

[3] Wang, L. On the Application of Scaffolding Teaching in Translation Teaching Practice.

[4]Xiao, L., Ren, Z. The Application of Scaffolding Teaching Method in English Translation Teaching.

[5]Hang, H. The Application of "Scaffolding" Teaching Theory in Translation Teaching.

[6]Elisa, C. Scaffolding translation skills through situated training approaches: progressive and reflective methods.

[7] Anne, K., Niklas, P. Translation activities in bilingual early childhood education: Children's perspectives and teachers' scaffolding.

[8] Alireza, A., Monir, G., Winibert, S. Situatedness and Translation Training: Scaffolding Skills and Progressive Methods.

[9]Liu, Y. Approaches and Models Involving the Concept of Instructional Scaffolding.

[10]Pitkänen, K., Iwata, M., Laru, J. Exploring 
technology-oriented Fab Lab facilitators' role as educators in K-12 education: Focus on scaffolding novice students' learning in digital fabrication activities.

[11]Park, Tiwari, Neumann. Emotional scaffolding in early childhood education.

[12]Isaiah, T., Mark, P., Uwana, E. Visual Organizers and Scaffolding the Student Learning Experience in Higher Education.
[13]Jeanette, N., Helen, C., Sheona, T. Towards Agility: Scaffolding Anticipative Education in Social Work.

[14]Nguyen, M., Penry, W. A preservice teacher's learning of instructional scaffolding in the EAL practicum.

[15]Zhang, Z. An Analysis of Ways to Improve Students' English Application Ability in Collifege English Translation Teaching. 